Polish Journal of Microbiology

2016, Vol. 65, No 2, 171-176

ORIGINAL PAPER

\title{
Biocontrol of Gray Mold Decay in Pear by Bacillus amyloliquefaciens Strain BA3 and its Effect on Postharvest Quality Parameters
}

\author{
HUI QU*, LONGYU ZHAO*, FENGCHUN ZHAO, YUFANG LIU and ZHENGYOU YANG** \\ Department of Microbiology, College of Life Science, Key Laboratory for Agriculture Microbiology, \\ Shandong Agricultural University, Taian, China
}

Submitted 29 October 2015, revised 13 November 2015, accepted 30 November 2015

\begin{abstract}
The economic losses caused by postharvest fruits diseases have attracted global attention. Traditional chemical fungicide could not meet the need of humans. In recent years, microbial agent which has begun to take the place of chemical fungicide comes into people's vision. The aim of this paper was to investigate the potential of Bacillus amyloliquefaciens strain BA3 for its biocontrol capability on gray mold decay of pears and its effect on postharvest quality of pears. Compared with other treatments, the inhibition effect on gray mold of washed cell suspension of B. amyloliquefaciens was the best. Consequently it was utilized in subsequent experiments. Spore germination and germ tube length of Botrytis cinerea was $18.72 \%$ and $12.85 \mu \mathrm{m}$ treated with BA3, while the control group was $62.88 \%$ and $30.44 \mu \mathrm{m}$. We confirmed that increase of the concentration of B. amyloliquefaciens, improved the efficacy of BA3 in controlling gray mold decay of pears. Colonization variation of BA3 in wounds of pears was recorded. To begin with, the populations of B. amyloliquefaciens increased rapidly and remained stable. On the fourth day, there was a declining trend, after that the population increased to $4 \times 10^{5} \mathrm{CFU} /$ wound and remained stable. BA3 had no significant effect on mass loss, titratable acidity, firmness and total soluble solids of pears that were stored at $25^{\circ} \mathrm{C}$ for 7 days comparing with control group. However, the effect of B. amyloliquefaciens on ascorbic acid was significantly higher than that of the control group. Our study indicates that B. amyloliquefaciens has a potential as postharvest biocontrol agent on pears.
\end{abstract}

Ke y w o r d s: Bacillus amyloliquefaciens, Botrytis cinerea, biocontrol agents, gray mold, quality parameters

\section{Introduction}

Postharvest diseases are the primary damages of fruits during cultivation, transportation and storage. Postharvest decay of fruits has caused significant levels of economic losses worldwide (Sugar and Basile, 2011; Luo et al., 2015). It is reported that in developed countries $20-25 \%$ of harvested fruits decay because of postharvest diseases and 50\% in developing countries (Sharma et al., 2009; Lutz et al., 2013).

The pear is one of the world's cultivated fruits, more than 70 countries and regions all over the world produce pears. In recent years, the cultivation area and the production of pears increased rapidly in China, which has been ranked first in the world (Yang et al., 2015).

Gray mold decay spreads widely and is caused by Botrytis cinerea which becomes one of the most important postharvest pear diseases (Lutz et al., 2013). Currently, postharvest diseases are controlled mainly by chemical means (Zhang et al., 2008a). However, chemi- cal control is unfriendly to the environment and even leads to hazardous effects on humans and the environment (Solanki et al., 2013). Due to the increasing public concern about the potential detrimental effects of synthetic fungicides abuse, it is necessary to explore the best pollution-free means to control postharvest diseases (Sansone et al., 2005; Liu et al., 2010; Liu et al., 2013). Microbial biocontrol agents show great potential for controlling postharvest decay of fruits as an alternative to chemical control (Fan and Tian, 2000).

Bacillus species can be isolated from a variety of substances and it has been proved that they can produce inhibiting substances acting against a wide range of pathogens (Arguelles-Arias et al., 2009; Solanki et al., 2012; 2013). The objective of this study was focused on the Bacillus amyloliquefaciens strain BA3 isolated from "douchi", controlling postharvest decay of pears by B. amyloliquefaciens and exploring: (1) biocontrol activity of B.amyloliquefaciens in vitro, (2) efficacy of B.amyloliquefaciens on conidial germination of

* These authors contributed equally.

** Corresponding author: Z. Yang, Department of Microbiology, College of Life Science, Key Laboratory for Agriculture Microbiology, Shandong Agricultural University, Taian, China; e-mail: zhyouyang@sdau.edu.cn 
B. cinerea, (3) population studies of B. amyloliquefaciens in wounds, (4) efficacy of B. amyloliquefaciens on control of gray mold decay of pears, (5) efficacy of B. amyloliquefaciens on quality attributes of postharvest pears.

\section{Experimental}

Materials and Methods

Pathogen inoculum. B. cinerea Pers, purchased from Guangdong Microbiology Culture Center (GIMCC), was cultivated on synthetic potato medium (extract of boiled potatoes, $200 \mathrm{ml}$; dextrose, $20 \mathrm{~g}$; $\mathrm{KH}_{2} \mathrm{PO}_{4}, 3 \mathrm{~g}$; $\mathrm{MgSO}_{4} \cdot 7 \mathrm{H}_{2} \mathrm{O}, 1.5 \mathrm{~g}$; vitamin $\mathrm{B} 1,8 \mathrm{mg}$; agar powder, $20 \mathrm{~g}$ and deionized water, $800 \mathrm{ml} ; \mathrm{pH}, 6$ at $25^{\circ} \mathrm{C}$ for 7 days. To prepare a spore suspension of $B$. cinerea, the plates were flushed with $10 \mathrm{ml}$ sterile distilled water, and then the spore concentration was determined with a hemacytometer and adjusted to required concentration.

Antagonist. B. amyloliquefaciens strain BA3, was isolated from "douchi" (a kind of Chinese soy products) and identified by BioSune Company (Shanghai, China). GenBank number is KF192921. BA3 was incubated on NA (Nutrient Agar: peptone, 5 g; beef extract, $30 \mathrm{~g}$; $\mathrm{NaCl}, 5 \mathrm{~g}$; agar powder, $15 \mathrm{~g} ; 1000 \mathrm{ml}$ distilled water; $\mathrm{pH}, 7.0-7.2$ ) at $28^{\circ} \mathrm{C}$. B. amyloliquefaciens strain BA3 was cultivated in $250 \mathrm{ml}$ Erlenmeyer flasks with $50 \mathrm{ml}$ of NB (NA without agar powder) which had been inoculated with a loop of the culture on a rotary shaker at $200 \times \mathrm{g}$ for $24 \mathrm{~h}$ at $28^{\circ} \mathrm{C}$. Then four treatments of liquid cultures were used: (A) liquid cultures (LC): mentioned above; (B) autoclaved cultures (AC): autoclaving the liquid cultures for $20 \mathrm{~min}$ at $121^{\circ} \mathrm{C}$; (C) Culture filtrates $(\mathrm{CL})$ : filtering centrifuged liquid supernatant of the antagonist through a $0.2 \mu \mathrm{m}$ polycarbonate membrane filter; (D) washed cell suspension (WCS): the cells were harvested by centrifugation at $8000 \times \mathrm{g}$ for $10 \mathrm{~min}$, washed twice and then re-suspended with distilled water. The concentration of cells in the suspension was counted with a hemacytometer and adjusted to $1 \times 10^{8} \mathrm{CFU} / \mathrm{ml}$ with sterile distilled water and (E) sterile distilled water acted as the control (CK).

Fruits. Pear fruits (Pyrus pyrifolia) cultivar "huangguan" were harvested at commercial maturity, selected on uniformity size without physical injuries or infections. Steep the fruit for $2 \mathrm{~min}$ in $0.1 \%$ sodium hypochlorite to sterilize and air dry before being wounded.

In vitro antagonism. To estimate the interactions between the antagonist and the pathogen in vitro, we coated $200 \mu \mathrm{l}$ spore suspension of B. cinerea on synthetic potato medium plates with a glass rod evenly. Then cut a 3-mm-diameter disk from the plates and added $100 \mu \mathrm{l} \mathrm{A}$-E suspensions of treatments into each well. One hour later, the plates were incubated at $28^{\circ} \mathrm{C}$
(Liu et al., 2010). The inhibition zone diameters were recorded after 7 days. Each test consisted of three replicate trials of 3 plates. The test was repeated three times.

Efficacy of BA3 on conidial germination of B. cinerea. The efficacy of BA3 on spore germination and germ tube elongation of B. cinerea was assessed in potato dextrose broth (PDB) (Feng et al., 2011). One hundred $\mu$ l spore suspension of $B$. cinerea $\left(1 \times 10^{6}\right.$ spores $/ \mathrm{ml}$ ) was added to glass tubes containing $4.8 \mathrm{ml}$ of PDB. One hundred $\mu$ l quantity of $1 \times 10^{8} \mathrm{CFU} / \mathrm{ml}$ of B. amyloliquefaciens suspension or sterile distilled water (as control) was added into each tube, respectively. After 12 hours' incubation at $28^{\circ} \mathrm{C}$ on a rotary shaker $(200 \times \mathrm{g})$, a total of 100 spores per replicate were observed microscopically with a light microscope and at least 5 microscope fields were observed. Conidia were considered germinated when the germ tube length was equal to or longer than the conidia length (Lutz et al., 2013). All treatments consisted of three replicates, and experiments were repeated three times.

Population studies of B. amyloliquefaciens strain BA3 on fruit wounds. A uniform $5 \mathrm{~mm}$ deep and $3 \mathrm{~mm}$ wide wound was made at the equator of each fruit (put on its side) using the tip of a sterile inoculating needle. We injected $20 \mu \mathrm{l}$ cell suspension of BA3 $\left(1 \times 10^{8} \mathrm{CFU} /\right.$ $\mathrm{ml})$ into the wound of each pear. Then the treated pears were cultivated at $25^{\circ} \mathrm{C}(90 \%$ relative humidity). Population of BA3 was recorded after being incubated for 0 ( $2 \mathrm{~h}$ after treatment), 1, 2, 3, 4, 5, 6 and 7 days, respectively. Wounded tissue was removed with an sterile $7 \mathrm{~mm}$ (internal diameter) cork borer and ground with an autoclaved mortar and pestle in $50 \mathrm{ml}$ of sterile $0.85 \%$ sodium chloride solution. Serial tenfold dilution was made and $0.1 \mathrm{ml}$ of each dilution was spread in NA. The plates were incubated at $28^{\circ} \mathrm{C}$ for 2 days and the colonies were counted. Population densities of B. amyloliquefaciens BA3 were expressed as $\log _{10} \mathrm{CFU}$ per wound. There were three single fruit replicates per treatment, and the experiments were repeated three times (Yu et al., 2012).

Efficacy of BA3 in controlling of gray mold decay of pears. A uniform $5 \mathrm{~mm}$ deep and $3 \mathrm{~mm}$ wide wound was made at the equator of each fruit (put on its side) using the tip of a sterile inoculating needle. The cell suspension of BA3 was adjusted to gradient concentration consisting of $1 \times 10^{6}, 1 \times 10^{7}, 1 \times 10^{8} \mathrm{CFU} / \mathrm{ml}$ with sterile distilled water by hemacytometer, respectively. We added thirty microliters washed cell suspension of $1 \times 10^{6}, 1 \times 10^{7}, 1 \times 10^{8}$ and 0 (as control) CFU/ml into each wound, respectively. After two hours, we injected fifteen microliters of spore suspension of B.cinerea $\left(1 \times 10^{5} \mathrm{spores} / \mathrm{ml}\right)$ to each wound. Treated fruits were stored at $25^{\circ} \mathrm{C}$ for 7 days or $0^{\circ} \mathrm{C}$ for 30 days after airdrying. Infection rates and lesion diameters on fruits were measured. There were three replicate trials of 
10 fruits per treatment with complete randomization in each test. The test was repeated twice.

Quality parameters of postharvest pears treated with BA3. To appraise the effect of B. amyloliquefaciens on quality attributes of postharvest pear, the pear fruits were soaked in washed cell suspensions $\left(1 \times 10^{8} \mathrm{CFU} / \mathrm{ml}\right)$ or sterile distilled water as a control respectively for 30 second, and then air-dried. The treated fruits were stored in artificial climate chamber with polyethylenelined plastic boxes to retain high relative humidity at $25^{\circ} \mathrm{C}$ for 7 days. After storage, quality attributes were measured. Quality attributes of postharvest treated pears were made on three replicates of five fruits each, the test was repeated twice.

Mass loss. The weight of pear was measured by a JA31002 balance $( \pm 0.01 \mathrm{~g})$ (Shanghai Jingping Balance Instruments, China) before treatment (A) and after storage (B), respectively, and the mass loss was calculated as (A-B)/A (Zhang et al., 2008b).

Ascorbic acid. The 2, 6-dichloroindophenol titrimetric method (AOAC) was used to determine the ascorbic acid content of pressed fruit juice. Results were expressed as milligrams of ascorbic acid/100 g sample (AOAC, 1995).

Titratable acidity. Titratable acidity was determined by the method described by Özden and Bayindirli (2002). Titratable acidity was calculated as the percent of malic acid.

Fruit firmness. Firmness values of each pear were measured at three points. Insert a fruit ripeness tester (Wagner Instruments) by $90^{\circ}$ at the equator of each fruit after the removal of $1 \mathrm{~mm}$ thick slice of peel. The firmness of each pear was measured three times on different sides.

Total soluble solids (TSS). We measured total soluble solids (TSS) with a hand-held refractometer, and recorded the refractive index of the same juice. The results were expressed as percentages (g per $100 \mathrm{~g}$ fruit weight) (Luo et al., 2015).

Statistical analysis. Statistical analyses were performed with SPSS version 19.0. The data were analyzed by analysis of the variance (ANOVA). Statistical significance was assessed at P-value $<0.01$ and Duncan's Multiple Range Test was used to separate means.

\section{Results and Discussion}

Microorganism is a kind of useful biocontrol agent that can inhibit several pathogens fungi which cause postharvest diseases of fruits (Chen etal., 2009; Li et al., 2011; Askarne et al., 2012; Solanki et al., 2012; Yu et al., 2012; Hu et al., 2015). But to our knowledge, there is little information concerning about the effect of B. amyloliquefaciens on controlling postharvest gray

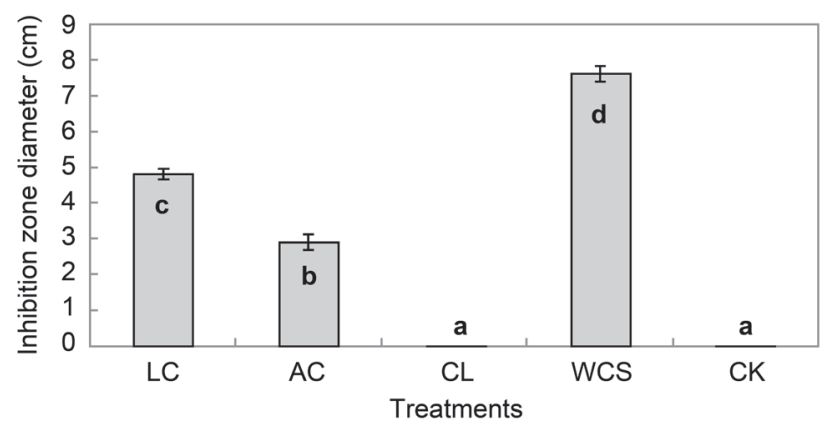

Fig. 1. Efficacy of different treatments in controlling of growth of $B$. cinerea on plates.

LC, liquid cultures; AC, autoclaved cultures; CL, Culture filtrates; WCS, $1 \times 10^{8} \mathrm{CFU} / \mathrm{ml}$ washed cell suspension; CK, sterile distilled water. Inhibition zone diameters were measured after 7 days at $28^{\circ} \mathrm{C}$. Means are averaged values of three trials \pm standard error. Bars represent standard errors. Values followed by different lowercase letters are significantly different at the 0.01 probability level according to analysis by Duncan's multiple range tests.

mold decay of pears and the influence of B. amyloliquefaciens on quality parameters of pears. Thus, it is in need of exploring the efficacy of B. amyloliquefaciens in control of gray mold decay and its effect on postharvest quality attributes of pears.

Antagonism in vitro. On synthetic potato medium plates, the inhibition zone diameter of washed cell suspension of BA3 was $7.6 \mathrm{~cm}$ (Fig. 1) and was significantly larger than that of control and other treatments. Liquid cultures and autoclaved cultures also significantly inhibited the development of $B$. cinerea. Inhibition zone diameters, respectively, were $4.8 \mathrm{~cm}$ and $2.9 \mathrm{~cm}$. But those were significantly smaller than that of washed cell suspension. Culture filtrates and sterile distilled water did not have any inhibitory effect on B. cinerea so the inhibition zone diameters were $0 \mathrm{~cm}$.

The inhibition zone diameters of washed cell suspension of BA3 were obviously larger than control and all the other treatments and it indicated the cell suspension was the best agent among what we have used against B. cinerea (Hu et al., 2015). So the cell suspension was utilized in the next experiments.

Efficacy of BA3 on conidial germination of B. cinerea. The spore germination of control was $62.88 \%$ after incubated at $28^{\circ} \mathrm{C}$ for 20 hours, and the germination of treatment was $18.72 \%$. At the same time, the germ tube length of $B$. cinerea of control was $30.44 \mu \mathrm{m}$, which of treatment was $12.85 \mu \mathrm{m}$ (Table I).

B. amyloliquefaciens significantly controlled spore germination and germ tube length of B. cinerea. Lutz et al. (2013) indicated that there are differences between different strains' inhibiting effect and different pathogens. The germination inhibition percentage of BA3 is higher than most yeast strains in Lutz et al. (2013) and Spadaro et al. (2013). Several biocontrol mechanisms have been suggested as being effective against postharvest fruit diseases (Jamalizadeh et al., 2011), 
Table I

Efficacy of B. amyloliquefaciens strain BA3 on conidial germination of B. cinerea

\begin{tabular}{|l|c|c|}
\hline \multicolumn{1}{|c|}{ Treatments } & $\begin{array}{c}\text { Spore germination } \\
(\%)\end{array}$ & $\begin{array}{c}\text { Germ tube length } \\
(\mu \mathrm{m})\end{array}$ \\
\hline Control & $62.88 \pm 3.78 \mathrm{a}$ & $30.44 \pm 1.79 \mathrm{a}$ \\
\hline B. amyloliquefaciens & $18.72 \pm 1.26 \mathrm{~b}$ & $12.85 \pm 0.75 \mathrm{~b}$ \\
\hline
\end{tabular}

Germination rate and germ tube length were measured after $20 \mathrm{~h}$ incubation at $28^{\circ} \mathrm{C}$ in PDB. Means are averaged values of three trials \pm standard error. Values followed by different lowercase letters are significantly different at the 0.01 probability level according to analysis by Duncan's multiple range tests. The same as below.

competition for nutrients is the possible mechanism that BA3 inhibit the spore germination.

Population studies of BA3 on fruit wounds. At the start of the experiment (time 0 ), the population of B. amyloliquefaciens was $6 \times 10^{4} \mathrm{CFU} /$ wound, and then it increased rapidly to $4.7 \times 10^{6} \mathrm{CFU} /$ wound (Fig. 2).

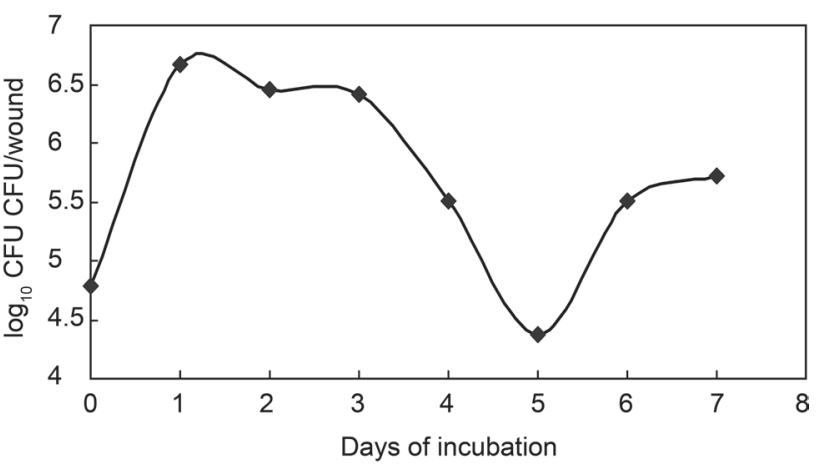

Fig. 2. Population dynamics of B. amyloliquefaciens on fruit wounds incubated at $25^{\circ} \mathrm{C}$.

Data were pooled from three experiments and each point representing the mean colony counts from three replicate fruits.

In the following three days ( $1^{\text {st }}$ day to $3^{\text {rd }}$ day), the populations remained stability basically. But on the fourth day, there was a declining trend of. When on the fifth day, B. amyloliquefaciens population touched bottom of $2.4 \times 10^{4} \mathrm{CFU} /$ wound, then increased to $4 \times 10^{5} \mathrm{CFU} /$ wound and kept stable.
To select an antagonist suitable for postharvest application, it is necessary to look for what can be adapted for the environment of wounds and make use of nutrient sources, then grow it and proliferate it well (Manso and Nunes, 2011; Yu et al., 2013). The population of B. amyloliquefaciens strain BA3 increased rapidly and remained stability on the wounds of pears in the first three days which demonstrated that BA3 has the potential as an antagonist. But the population declined to $2.4 \times 10^{4} \mathrm{CFU} /$ wound on the fourth day. The pathogens might attach to the wounds, begin to grow, and then compete for nutrition and space against B. amyloliquefaciens. Afterwards the antagonist became the dominant bacteria and the population of BA3 kept stable. These suggested that the competition for nutrient sources and space may be one of the mechanisms of action to inhibit the pathogen. This result is different from Zhang et al. (2008a) and Hu et al. (2015). It is probable that B. amyloliquefaciens needs a transitional period to control the pathogens.

Efficacy of BA3 in control of gray mold decay of pears. After incubation at $25^{\circ} \mathrm{C}$ for 7 days, the infection rate of control fruit was $100 \%$. And at the concentration of B. amyloliquefaciens of $1 \times 10^{8} \mathrm{CFU} / \mathrm{ml}$, it decreased to $53 \%$, which was significantly lower than the control (Table II). The infection rate of the concentration of B. amyloliquefaciens at $1 \times 10^{8} \mathrm{CFU} / \mathrm{ml}$ was not significantly lower than $1 \times 10^{7} \mathrm{CFU} / \mathrm{ml}$, but data indicated that the lesion diameters at $1 \times 10^{8} \mathrm{CFU} /$ $\mathrm{ml}$ were significantly smaller than at $1 \times 10^{7} \mathrm{CFU} / \mathrm{ml}$. Moreover, lesion diameter of the control was $4.80 \mathrm{~cm}$, which of B.amyloliquefaciens at the concentration of $1 \times 10^{8} \mathrm{CFU} / \mathrm{ml}$ was significantly smaller than the control, being $0.91 \mathrm{~cm}$. After cultivation for 30 days at $0^{\circ} \mathrm{C}$, the infection rate of the control was $86.3 \%$, while at concentration $1 \times 10^{8} \mathrm{CFU} / \mathrm{ml}$ it was significantly lower than the control, being $29.8 \%$. Being different from cultivated at $25^{\circ} \mathrm{C}$, infection rate at $1 \times 10^{8} \mathrm{CFU} / \mathrm{ml}$ was significantly lower than that at $1 \times 10^{7} \mathrm{CFU} / \mathrm{ml}$. However, the lesion diameters of the concentration at $1 \times 10^{6} \mathrm{CFU} / \mathrm{ml}$ and $1 \times 10^{7} \mathrm{CFU} / \mathrm{ml}$ did not show significant differences. Both infection rate and lesion

Table II

Efficacy of B. amyloliquefaciens strain BA3 in control of gray mold decay of pears

\begin{tabular}{|l|c|c|c|c|}
\hline \multirow{2}{*}{$\begin{array}{c}\text { Concentrations of } \\
\text { B. amyloliquefaciens } \\
(\mathrm{CFU} / \mathrm{ml})\end{array}$} & \multicolumn{2}{|c|}{$25^{\circ} \mathrm{C}$} & \multicolumn{2}{c|}{$0^{\circ} \mathrm{C}$} \\
\cline { 2 - 5 } & $\begin{array}{c}\text { Infection rate } \\
(\%)\end{array}$ & $\begin{array}{c}\text { Lesion diameter } \\
(\mathrm{cm})\end{array}$ & $\begin{array}{c}\text { Infection rate } \\
(\%)\end{array}$ & $\begin{array}{c}\text { Lesion diameter } \\
(\mathrm{cm})\end{array}$ \\
\hline $0(\mathrm{CK})$ & $100 \pm 0 \mathrm{a}$ & $4.80 \pm 0.06 \mathrm{a}$ & $86.3 \pm 1.26 \mathrm{a}$ & $4.18 \pm 0.19 \mathrm{a}$ \\
\hline $1 \times 10^{6}$ & $91.5 \pm 3.38 \mathrm{~b}$ & $3.82 \pm 0.11 \mathrm{~b}$ & $61.2 \pm 1.68 \mathrm{~b}$ & $2.73 \pm 0.08 \mathrm{~b}$ \\
\hline $1 \times 10^{7}$ & $68.2 \pm 4.44 \mathrm{c}$ & $2.78 \pm 0.27 \mathrm{c}$ & $47.8 \pm 1.40 \mathrm{c}$ & $2.37 \pm 0.09 \mathrm{~b}$ \\
\hline $1 \times 10^{8}$ & $53.0 \pm 5.38 \mathrm{c}$ & $0.91 \pm 0.14 \mathrm{~d}$ & $29.8 \pm 1.30 \mathrm{~d}$ & $0.75 \pm 0.11 \mathrm{c}$ \\
\hline
\end{tabular}

Infection rate and lesion diameter were recorded after storage at $25^{\circ} \mathrm{C}$ for 7 days or $0^{\circ} \mathrm{C}$ for 30 days. 
Table III

Efficacy of B. amyloliquefaciens strain BA3 on postharvest quality parameters of pears

\begin{tabular}{|l|c|c|c|c|c|}
\hline \multicolumn{1}{|c|}{ Treatments } & $\begin{array}{c}\text { Mass loss } \\
(\%)\end{array}$ & $\begin{array}{c}\text { Ascorbic acid } \\
(\mathrm{mg} / 100 \mathrm{~g})\end{array}$ & $\begin{array}{c}\text { Titratable acidity } \\
(\% \text { malic acid })\end{array}$ & $\begin{array}{c}\text { Fruit firmness } \\
(\mathrm{N})\end{array}$ & $\begin{array}{c}\text { Total soluble solids } \\
(\%)\end{array}$ \\
\hline Control & $1.74 \pm 0.49 \mathrm{a}$ & $0.651 \pm 0.056 \mathrm{a}$ & $0.067 \pm 0.0053 \mathrm{a}$ & $11.96 \pm 0.40 \mathrm{a}$ & $11.11 \pm 0.423 \mathrm{a}$ \\
\hline Antagonist & $1.25 \pm 0.04 \mathrm{a}$ & $0.881 \pm 0.083 \mathrm{~b}$ & $0.078 \pm 0.0070 \mathrm{a}$ & $13.24 \pm 0.40 \mathrm{a}$ & $11.22 \pm 0.324 \mathrm{a}$ \\
\hline
\end{tabular}

diameter of each concentration at $0^{\circ} \mathrm{C}$ were smaller than at $25^{\circ} \mathrm{C}$.

The results reported in Table II show that, the concentration of BA3 significantly influenced the development of B. cinerea in pear. Hu etal. (2015) and $\mathrm{Li}$ et al. (2011) demonstrated that the higher the concentration of B. amyloliquefaciens, the lower the infection rate and the smaller the lesion diameter. Similarly, there is a direct correlation between the concentration of B. amyloliquefaciens strain BA3 and biocontrol effectiveness. When the concentration of B. amyloliquefaciens was $1 \times 10^{8} \mathrm{CFU} / \mathrm{ml}$, the infection rate was reduced almost by one half, and the lesion diameters were contained within $1 \mathrm{~cm}$.

Since most fruits are stored at low temperatures to extend shelf-life, being able to inhibit decay at low temperatures condition is the criterion for selecting an antagonist (Manso and Nunes, 2011). Stored at $0^{\circ} \mathrm{C}$, the effect of BA3 in controlling of gray mold decay is better than at $25^{\circ} \mathrm{C}$, suggesting that B. amyloliquefaciens had great potential in inhibiting gray mold decay of pears and could be utilized as a biological control agent at low temperatures.

According to studies conducted by Lutz et al. (2013), limiting spore germination of pathogens may be one of the major mechanisms of action of B. amyloliquefaciens. However, the interactions among host, pathogen, antagonist and microorganisms are complicated (Liu etal., 2010), and the action mechanisms of antagonists against pathogens are not single (Arguelles-Arias et al., 2009). This requires further research and more accurate descriptions.

Quality parameters of postharvest pears treated with BA3. According to Table III, the pears treated with B. amyloliquefaciens showed no significant differences with regard to mass loss, titratable acidity, firmness and total soluble solids compared with the control. But the ascorbic acid of pears treated with B. amyloliquefaciens was significantly higher than that of control fruits.

Not impairing the quality attributes of fruits is one of the conditions of an ideal biocontrol agent (Liu et al., 2010). Moreover, the ascorbic acid of pears treated with $B$. amyloliquefaciens was significantly enhanced. This is different from other literature data (Özden and Bayindirli, 2002; Zhang et al., 2008a; Luo et al., 2015) which discussed the effect of antagonists on quality parameters of postharvest fruits. All of this further illustrates that B.amyloliquefaciens strain BA3 has a commercial potential.

In our experiments, B. amyloliquefaciens was isolated from the "douchi" and therefore is not harmful to human health. All of the results from the study indicate that B.amyloliquefaciens strain BA3 has the potential to be used as a biological control agent.

Our experiments did not fully assess the effect of B. amyloliquefaciens in control of gray mold decay of fruits, considering storage conditions or the mixture of other materials that improve the biocontrol efficacy so as to explore better means of biocontrol. We should also focus our further studies on the commercial application of B. amyloliquefaciens.

\section{Acknowledgements}

This study was supported by National Natural Science Foundation of China (grant numbers 30972050, 31271873) and the Scientific Research Foundation for the Returned Overseas Chinese Scholars, State Education Ministry.

\section{Literature}

AOAC. 1995. Official Methods of Analysis, $16^{\text {th }}$ edn. 45.1.14. AOAC, Arlington, Virginia.

Arguelles-Arias A., M. Ongena, B. Halimi, Y. Lara, A. Brans, B. Joris and P. Fickers. 2009. Bacillus amyloliquefaciens GA1 as a source of potent antibiotics and other secondary metabolites for biocontrol of plant pathogens. Microb. Cell Fact. 8: 63-74.

Askarne L., I. Talibi, H. Boubaker, E.H. Boudyach, F. Msanda, B. Saadi and A. Ait Ben Aoumar. 2012. Use of Moroccan medicinal plant extracts as botanical fungicide against citrus blue mould. Lett. Appl. Microbiol. 56: 37-43.

Chen X.H., R. Scholz, M. Borriss, H. Junge, G. Mogel, S. Sunz and R. Borriss. 2009. Difficidin and bacilysin produced by plantassociated Bacillus amyloliquefaciens are efficient in controlling fire blight disease. J. Biotechnol. 140: 38-44.

Fan Q. and S.P. Tian. 2000. Postharvest biological control of rhizopus rot of nectarine fruits by Pichia membranefaciens. Plant Dis. 84: 1212-1216.

Feng L.Y., F.W. Wu, J. Li, Y.M. Jiang and X.W. Duan. 2011. Antifungal activities of polyhexamethylene biguanide and polyhexamethylene guanide against the citrus sour rot pathogen Geotrichum citri-aurantii in vitro and in vivo. J. Basic Microbiol. 61: 160-164.

Hu H., F.J. Yan, C. Wilson, Q. Shen and X.D. Zheng. 2015. The ability of a cold-adapted Rhodotorula mucilaginosa strain from Tibet to control blue mold in pear fruit. http://link.springer.com/article/ 0.1007\%2Fs10482-015-0593-1. 2015.10.10.

Jamalizadeh M., H.R. Etebarian, H. Aminian and A. Alizadeh. 2011. A review of mechanisms of action of biological control 
organisms against post-harvest fruit spoilage. Bulletin $O E P P / E P P O$ 41: 65-71.

Li R., H. Zhang, W. Liu and X.D. Zheng. 2011. Biocontrol of postharvest gray and blue mold decay of apples with Rhodotorula mucilaginosa and possible mechanisms of action. Int. J. Food Microbiol. 146: $151-156$.

Liu H.M., J.H. Guo, Y.J. Cheng, L. Luo, P. Liu, B.Q. Wang, B.X. Deng and C.A. Long. 2010. Control of gray mold of grape by Hanseniaspora uvarum and its effects on postharvest quality parameters. Ann. Microbiol. 60: 31-35.

Liu J., Y. Sui, M. Wisniewski, S. Droby and Y. Liu. 2013. Review: Utilization of antagonistic yeasts to manage postharvest fungal diseases of fruit. Int. J. Food Microbiol. 167: 153-160.

Luo S.S., B. Wan, S.H. Feng and Y.Z. Shao. 2015. Biocontrol of Postharvest Anthracnose of Mango Fruit with Debaryomyces Nepalensis and Effects on Storage Quality and Postharvest Physiology. http://onlinelibrary.wiley.com/doi/10.1111/17 50-3841.13087/full. 2015.10.07.

Lutz M.C., C.A. Lopes, M.E. Rodriguez, M.C. Sosa and M.P. Sangorrín. 2013. Efficacy and putative mode of action of native and commercial antagonistic yeasts against postharvest pathogens of pear. Int. J. Food Microbiol. 164: 166-172.

Manso T. and C. Nunes. 2011. Metschnikowia andauensis as a new biocontrol agent of fruit postharvest diseases. Postharvest Biol. Technol. 61: 64-71.

Özden Ç. and L. Bayindirli. 2002. Effects of combinational use of controlled atmosphere, cold storage and edible coating applications on shelf life and quality attributes of green peppers. Eur. Food Res. Technol. 214: 320-326.

Sansone G., I. Rezza, V. Calvente, D. Benuzzi and M.I.S. Tosetti. 2005. Control of Botrytis cinerea strains resistant to iprodione in apple with rhodotorulic acid and yeasts. Postharvest Biol. Technol. 35: 245-251.

Sharma R., D. Singh and R. Singh. 2009. Biological control of post harvest diseases of fruits and vegetables by microbial antagonists: a review. Biol. Control. 50: 205-221.
Spadaro D., A. Lore, A. Garibaldi and M.L. Gullino. 2013. A new strain of Metschnikowia fructicola for postharvest control of Penicillium expansum and patulin accumulation on four cultivars of apple. Postharvest Biol. Technol. 75: 1-8.

Solanki M.K., A.S. Robert, R.K. Singh, S. Kumar, A.K. Pandey, A.K. Srivastava and D.K. Arora. 2012. Characterization of mycolytic enzymes of Bacillus strains and their bio-protection role against Rhizoctonia solani in tomato. Curr. Microbiol. 65: 330-336.

Solanki M.K., R.K. Singh, S. Srivastava, S. Kumar, P.L. Kashyap and A.K. Srivastava. 2013. Characterization of antagonistic-potential of two Bacillus strains and their biocontrol activity against Rhizoctonia solani in tomato. J. Basic Microbiol. 53: 1-9.

Sugar D. and S.R. Basile. 2011. Orchard calcium and fungicide treatments mitigate effects of delayed postharvest fungicide applications for control of postharvest decay of pear fruit. Postharvest Biol. Technol. 60: 52-56.

Yang Y.N., G.F. Yao, W.Q. Yue, S.L. Zhang and J. Wu. 2015. Transcriptome profiling reveals differential gene expression in proanthocyanidin biosynthesis associated with red/green skin color mutant of pear (Pyrus communis L.). Front. Plant Sci. 6: 795.

Yu T., C. Yu, H.P. Lu, M. Zunun, F.X. Chen, T. Zhou, K. Sheng and X.D. Zheng. 2012. Effect of Cryptococcus laurentii and calcium chloride on control of Penicillium expansum and Botrytis cinerea infections in pear fruit. Biol. Control. 61:169-175.

Yu C., T. Zhou, K. Sheng, L.Z. Zeng, C.Z. Ye, T. Yu and X.D. Zheng. 2013. Effect of pyrimethanil on Cryptococcus laurentii, Rhodosporidium paludigenum, and Rhodotorula glutinis biocontrol of Penicillium expansum infection in pear fruit. Int. J. Food Microbiol. 164: 155-160. Zhang H.Y., L. Wang, Y. Dong, S. Jiang, H.H. Zhang and X.D. Zheng. 2008a. Control of postharvest pear diseases using Rhodotorula glutinis and its effects on postharvest quality parameters. Int. J. Food Microbiol. 126: 167-171.

Zhang H.Y., L.C. Ma, L. Wang, S. Jiang, Y. Dong and X.D. Zheng. 2008 b. Biocontrol of gray mold decay in peach fruit by integration of antagonistic yeast with salicylic acid and their effects on postharvest quality parameters. Biol. Control. 47: 60-65. 